\title{
APRIMORAMENTO DE SIMULADOR DE CARGAS DE TRÁFEGO DO LABORATÓRIO DE GEOSSINTÉTICOS DA EESC-USP
}

\section{IMPROVEMENT OF THE TRAFFIC LOAD SIMULATOR OF THE GEOSYNTHETICS LABORATORY OF EESC-USP}

\section{Gabriel Orquizas Mattielo Pedroso1, Gabriel Ramos², Clever Aparecido Valentin ${ }^{3}$, Jefferson Lins da Silva ${ }^{4}$}

\author{
${ }^{1}$ Escola de Engenharia de São Carlos, Universidade de São Paulo (EESC-USP). gabpedroso@usp.br \\ ${ }^{2}$ Escola de Engenharia de São Carlos, Universidade de São Paulo (EESC-USP). gabriel2.ramos@usp.br \\ ${ }^{3}$ Escola de Engenharia de São Carlos, Universidade de São Paulo (EESC-USP). cclever@sc.usp.br \\ ${ }^{4}$ Escola de Engenharia de São Carlos, Universidade de São Paulo (EESC-USP). jefferson@sc.usp.br
}

Recebido:

08 de dezembro de 2020

Aceito para publicação:

10 de fevereiro de 2021

Publicado:

30 de março de 2021

Editor de área:

Cássio A. T. do Carmo

Palavras-chaves:

Simulador de Cargas de tráfego.

Desempenho de

Pavimento.

Pavimento Instrumentado.

\section{Keywords:}

Accelerated Loading Test.

Pavement Performance.

Instrumented Pavement.

DOI:

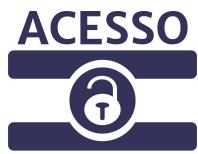

ABERTO

\section{RESUMO}

Este estudo apresenta o aprimoramento do Equipamento de Simulação de Cargas de Tráfego do Laboratório de Geossintéticos da USP/EESC, utilizado para monitorar seções instrumentadas de pavimento em ensaios acelerados, detalhando as modificações estruturais do equipamento e a nova configuração de carregamento aplicado. O principal objetivo desta pesquisa foi avaliar e monitorar a eficiência do equipamento e o desempenho de uma estrutura de pavimento construída em escala reduzida. Foi ensaiada uma estrutura com 10 $\mathrm{cm}$ de espessura de base sobre um subleito de baixa resistência, simulando 100.000 repetições de passagens de um veículo pesado, e instrumentada com LVDT's, células de tensão total e de carga para avaliação do comportamento das camadas e dos carregamentos aplicados. Neste estudo, o desempenho do pavimento foi avaliado a partir das respostas das instrumentações instaladas, no que tange ao afundamento na trilha de roda, ao módulo de deformabilidade das camadas de base e subleito, a deflexão na superfície do pavimento, e as tensões no subleito. Os resultados indicam que o aprimoramento do Simulador de Cargas de Tráfego apresentou eficiência na simulação, no monitoramento e na aquisição de dados para aferição do desempenho do pavimento quanto aos efeitos oriundos do tráfego, além de não apresentar falhas mecânicas ou estruturais de grande impacto no decorrer do ensaio.

\section{ABSTRACT}

This study presents the improvement of the Traffic Load Simulation Equipment from the EESC/USP Geosynthetics Laboratory, used to monitor pavement instrumented sections in accelerated pavement tests, detailing the equipment structural modifications and the new applied loading configuration. The main objective of this research was to evaluate and monitor the equipment behavior and the pavement performance built on a small-scale pavement structure. A structure with $10 \mathrm{~cm}$ of base thickness was tested on a low resistance subgrade, simulating 100,000 repetitions of passages of a heavy vehicle, and instrumented with LVDT's, total tension cells and load cells to assess the behavior of the layers and applied loads. In this study, the pavement performance is evaluated by the responses of the instruments installed during the tests, in relation to the rutting in the wheel track, the deformability module of the base and subgrade layers, the surface deflection, and the subgrade stresses. The results indicate that the improvement of the Traffic Load Simulator showed efficiency in the simulation, in the monitoring and in the data acquisition for pavement performance gauging the effects of traffic, in addition to not presenting mechanical or structural failures of great impact during the test. 


\section{INTRODUÇÃO}

A avaliação do desempenho dos pavimentos pode ser realizada em ensaios de campo, experimentos de laboratório e simulações numéricas. Estes três métodos fornecem diferentes perspectivas sobre os dados do desempenho do pavimento (Reck, 2009). No Brasil, destacam-se os ensaios laboratoriais de pavimento em grande escala que simulam carregamentos cíclicos desenvolvidos e realizados por: Antunes (2008); Silva (2009) e Kakuda (2010), desenvolvidos, respectivamente, na UNB, UFRJ e USP. Dentre os equipamentos citados a aplicação das cargas cíclicas é realizada por meio de um cilindro e uma placa rígida.

Os ensaios acelerados de cargas de tráfego (APT - Accelerated Pavement Testing) foram desenvolvidos com o intuito de permitir a reprodução, seja em grande escala ou em tamanho reduzido, das características estruturais de pavimentos e as solicitações às quais o pavimento está sujeito durante sua vida de serviço. A possibilidade de simulação do tráfego de veículos pesados sobre um pavimento em um ambiente controlado de laboratório faz do APT uma importante ferramenta na produção e aquisição de dados relativos ao estudo do desempenho de estradas pavimentadas ou não pavimentadas. Segundo Metcalf (1996), o APT é definido como a aplicação controlada de carregamentos em um protótipo de roda sobre estruturas de pavimentos para determinar a resposta e o desempenho destas estruturas sobre uma condição controlada, e acelerada, de acúmulo de deterioração em um tempo reduzido.

Em se tratando de ensaios APT realizados no Brasil, destaca-se o experimento realizado por Gonçalves (2002), desenvolvido na UFRGS, em que foi utilizado um equipamento denominado HVS (Heavy Vehicle Simulator) em uma pista experimental de verdadeira grandeza. Ensaios APT também podem ser de dimensões reduzidas, diminuindo o seu custo de implantação, como o realizado por Correia (2014), sendo este desenvolvido no Laboratório de Geossintéticos da EESC-USP. Após o trabalho de Correia (2014), o APT da EESC-USP passou por vários aprimoramentos por meio da realização de pesquisas de mestrado e doutorado, em processo de finalização pelos Engenheiros Civis Gabriel Orquizas Mattielo Pedroso e Gabriel Ramos, respectivamente. Sendo assim, o propósito deste trabalho é mostrar as potencialidades implementadas no simulador de tráfego para a mensuração do afundamento na trilha de roda, do módulo elástico vertical e das deflexões, também apresentar os ensaios complementares, como o ensaio de placa. Um ensaio piloto é apresentado para descrição quantitativa e qualitativa dos aprimoramentos e inclusões realizadas.

\section{ENSAIO ACELERADO DE PAVIMENTO}

Os Ensaios APT são realizados com o equipamento de simulação de tráfego desenvolvido no Laboratório de Geossintéticos da EESC-USP por Correia (2014). As principais diferenças desse equipamento é a possibilidade de aplicar solicitações na estrutura por meio de um protótipo de roda, e de ser em escala reduzida (laboratório), o que diminui o custo de implantação.

Desde o término da pesquisa de Correia (2014), o equipamento passou por modificações visando o aumento da resistência de seus componentes, a alteração na programação dos ciclos de aplicação de carga e a possibilidade de utilizar sua estrutura para ensaios de placa estática (Figura 1a).

O equipamento é composto por uma roda de empilhadeira ligada a um pórtico metálico fixado a uma caixa com dimensões internas de 1,82 m de comprimento, 1,42 m de largura e 1,80 m de altura. As dimensões verticais do equipamento e da caixa resultam em uma altura útil do pavimento de $1,40 \mathrm{~m}$. $\mathrm{O}$ sistema de aplicação de carga é composto por um pistão alimentado por uma bomba hidráulica capaz de promover carregamentos de até $21 \mathrm{kN}$. A roda possui 228,6 mm de diâmetro, está revestida por um pneu Trelleborg T -800, com $540 \mathrm{~mm}$ de diâmetro, $155 \mathrm{~mm}$ de largura, capacidade de enchimento de $1 \mathrm{MPa}$ e capacidade de carga de $18,5 \mathrm{kN}$. A velocidade de movimento do percurso da roda é controlada pelo motor 
hidráulico instalado no carro guia. Além disso, molas de aço instaladas no fím do percurso têm a função de suavizar o movimento de parada do conjunto e reduzir a intensidade dos impactos na estrutura metálica. $\mathrm{O}$ equipamento e seus componentes estão ilustrados na Figura 1(b).

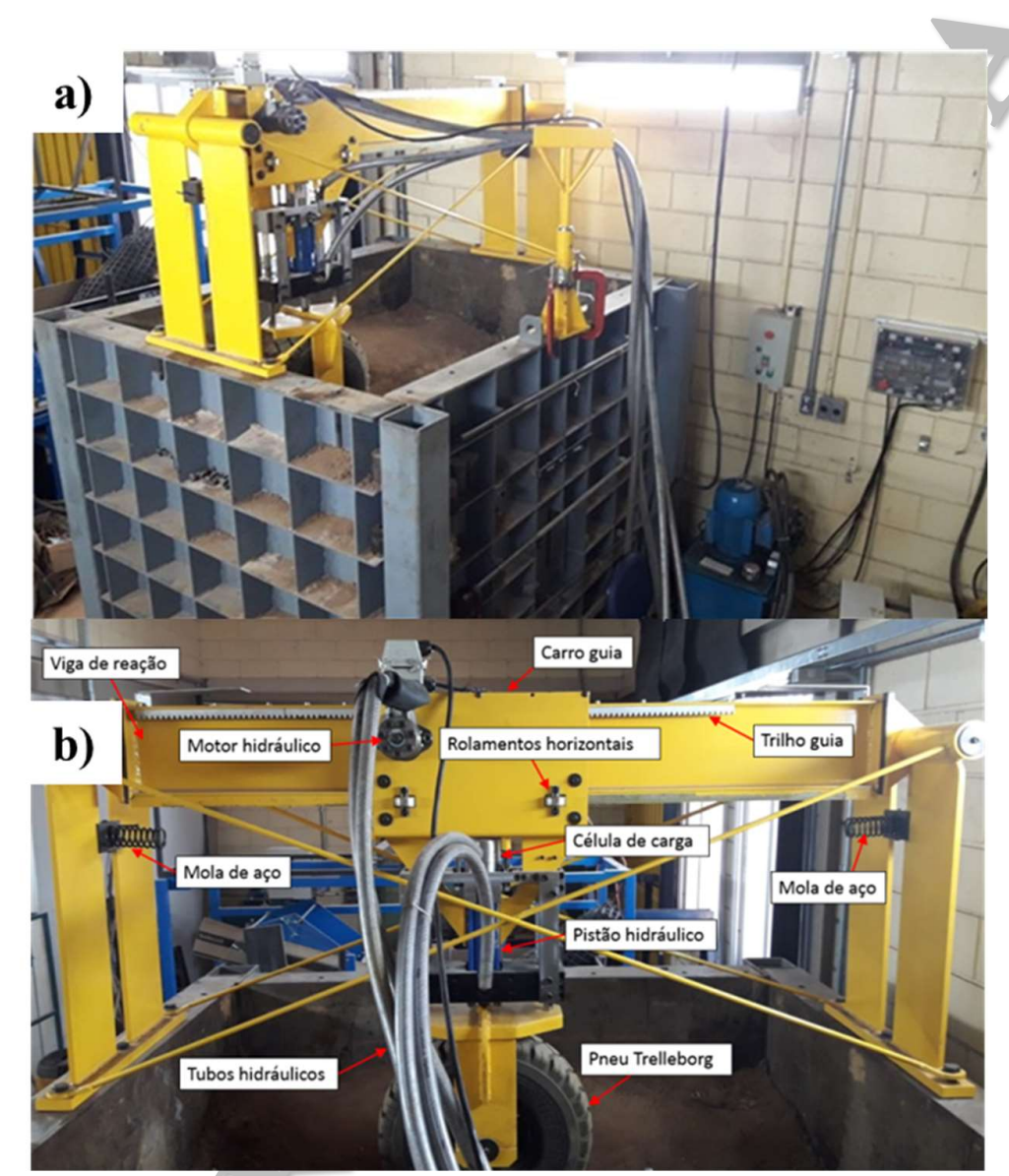

Figura 1: a) Vista geral; b) Detalhes do equipamento.

Com intuito de aumentar a resistência do equipamento, buscando minimizar a ocorrência de quebras e manutenções, a primeira alteração a se destacar no equipamento é com relação à conexão entre o pistão hidráulico e a roda. Buscou-se aumentar a área superficial do apoio da roda, o que permitiu a instalação de um sistema de guias mais robusto. Além disso, um bloco de estrutura de aço atrelado ao pistão hidráulico e duas barras de aço foram instaladas para reduzir os esforços. A Figura 2 (a) e (b) ilustram a alteração estrutural no equipamento.

A segunda alteração foi a instalação de sensores de indução por proximidade no carro guia e na estrutura de reforço do pistão hidráulico, conforme ilustrado na Figura 2 (c), que possibilitam o controle e automação do equipamento. Além das molas de aço, os sensores superiores controlam a frenagem do carro guia, e os sensores inferiores são responsáveis pela aceleração e controle do carregamento. Assim, as melhorias implementadas reduziram os impactos na estrutura do equipamento e pausas para manutenção, causadas devido a ruptura e/ou flexão do conjunto roda pistão, resultando em aumento da vida útil do equipamento. 


\section{Revista
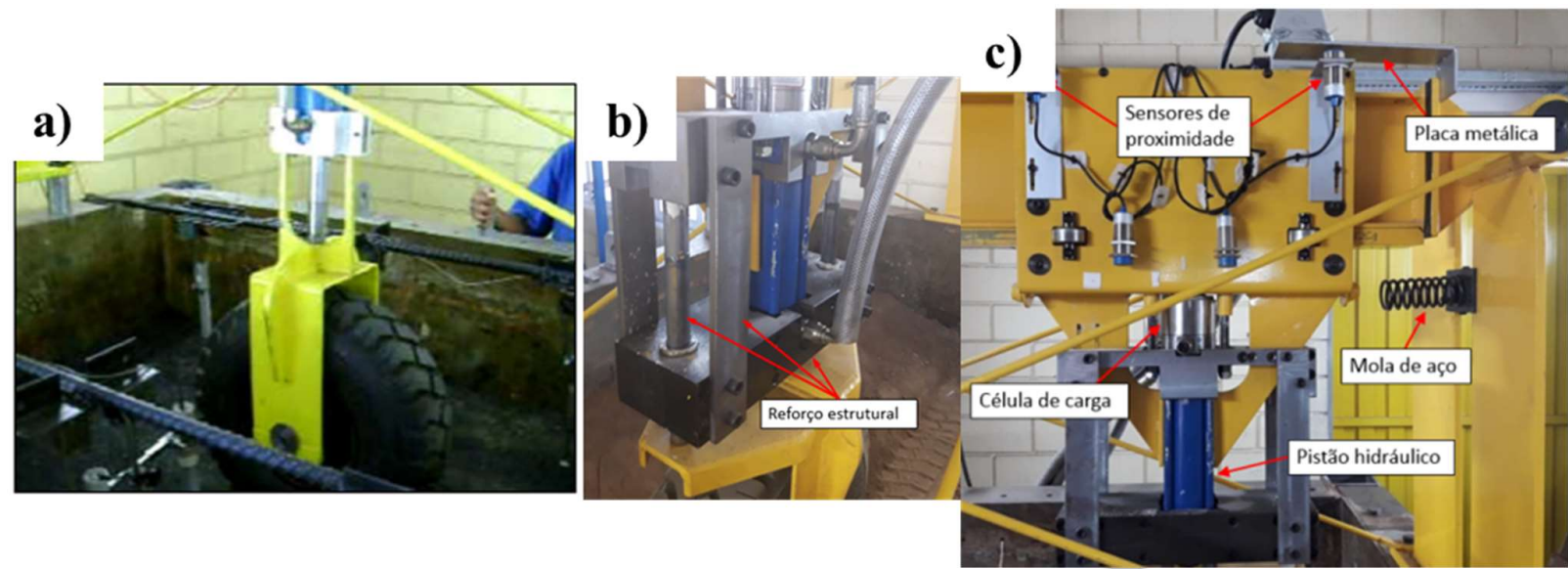

Figura 2: a) Configuração anterior (Correia, 2014); b) Configuração após reforço; c) Sensores de indução.

Além da mudança estrutural do equipamento, um novo programa de automação foi desenvolvido para controlar os movimentos do carro e a aplicação do carregamento. Utilizando uma placa de Arduíno, o sistema de hardware foi montado possibilitando contabilizar a quantidade de ciclos, e executar ciclos unidirecionais e bidirecionais. A configuração unilateral permite cerca de 500 ciclos por hora e a bidirecional 1000 ciclos por hora. Incluiu-se também a opção de controlar manualmente os movimentos do equipamento.

\subsection{Configuração do carregamento}

O APT desenvolvido é um equipamento em escala reduzida e por isso os carregamentos aplicados devem ser contabilizados com a dimensão da roda e do pneu, uma vez que, as características do equipamento diferem do eixo padrão rodoviário adotado como base para o cálculo do número N. Desta forma, com base no fator de escala do MMLS3 (one-third scale model mobile load simulator) utilizado por Tang e Palomino., (2013), ajustou-se a pressão de contato do pneu e o carregamento na roda.

O MMLS3 é um modelo em escala reduzida utilizado para ensaios APT, no qual é aplicado um carregamento de roda com $2,7 \mathrm{kN}$ com uma pressão de contato de $690 \mathrm{kPa}$, o que representa $1 / 9$ da carga padrão para uma roda e 1/4 para duas rodas. Por conta da redução de área de contato, as camadas do pavimento também são escaladas em $1 / 3$ da espessura real de campo. Entretanto, como as dimensões dos materiais utilizados na construção do APT não obedecem a uma escala numérica, espera-se um aumento na magnitude dos resultados.

Os carregamentos e as pressões de contato do experimento foram calibrados para que se obtenha uma pressão de contato de $690 \mathrm{kPa}$. Ressalta-se que Tielking e Roberts. (1987) apontaram duas formas de se obter a pressão de contato de um pneu em uma pequena região do pavimento: 1) carregamento vertical com o pneu parado; 2) com o pneu em movimento. Os autores também concluem que a pressão de enchimento do pneu exerce grande influência na forma e tamanho do contato entre o pneu/pavimento. Desta forma, a pressão de contato foi obtida de forma estacionária, onde a área de contato do pneu foi registrada (Figura 3) e posteriormente com o auxílio de um programa CAD calcula-se esta área. A partir da leitura do carregamento do equipamento e da área de contato calculada, calibra-se a pressão de contato. 


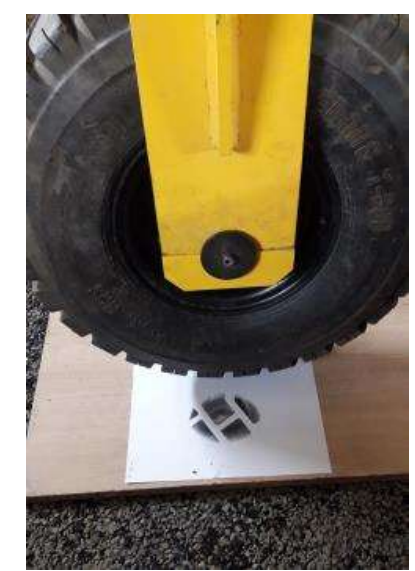

Figura 3: Registro da área de contato do pneu.

\subsection{Caracterização e montagem dos materiais de pavimentação}

Para o ensaio piloto no APT foi utilizada uma argila siltosa de baixa capacidade de suporte e alta plasticidade para o subleito, a caracterização e classificação do material é apresentada na Tabela 1. O material de subleito foi compactado com teor de umidade de $34 \%, 4,5 \%$ acima da umidade ótima, e apresentou um valor de CBR de $3,5 \%$ e $1,412 \mathrm{~g} / \mathrm{cm}^{3}$ de massa específica aparente seca na energia normal, com $98 \pm 1 \%$ de grau de compactação. Com base no estudo de Holtz et al. (1998), a escolha do teor de umidade acima da ótima é necessária para se obter um material com baixo CBR e altamente deformável, tendo em vista que a continuidade do trabalho envolve a utilização do reforço de geossintéticos para diminuir as deformações permanentes provenientes do subleito.

Tabela 1: Caracterização dos materiais.

\begin{tabular}{|c|c|c|c|c|c|c|c|c|c|c|c|}
\hline $\begin{array}{c}\text { Solo } \\
\text { Subleito }\end{array}$ & \multicolumn{8}{|c|}{ Caracterização } & \multicolumn{3}{|c|}{ Classificação } \\
\hline \multirow{2}{*}{ Subleito } & \%Argila & $\%$ Silte & \%Areia & $\rho s$ & $\mathrm{LL}$ & LP & IP & CBR(\%) & HBR & USCS & $\mathrm{MCT}$ \\
\hline & 60 & 30 & 10 & 2,89 & 62 & 39 & 23 & $3,5 \%$ & A-7-5 & $\mathrm{MH}$ & $\mathrm{NG}^{\prime}$ \\
\hline Base & 20 & 14 & 67 & 2,63 & 27 & 18 & 9 & $31 \%$ & A-2-4 & SC & LA' \\
\hline
\end{tabular}

*Normas utilizadas: NBR 6459 (1984), 7180 (1984), 7181 (1984), 7182 (1988); DNER-ME 254 (1997)

Para a base foi utilizada uma mistura de solo brita granulometricamente estabilizada com brita proveniente de basalto e um solo areno-argiloso, enquadrando-se na Faixa Granulométrica C do DER-SP ET-DE-P00/006 (2006), sendo uma mistura de $20 \%$ de solo e $80 \%$ de brita, em que os $80 \%$ de brita são compostos por $30 \%$ de pedra $1,15 \%$ de pedrisco e $35 \%$ de pó de brita. A mistura de solo brita apresentou $112 \%$ de CBR e $2,330 \mathrm{~g} / \mathrm{cm}^{3}$ de massa específica aparente seca máxima na energia modificada. A espessura da camada de base construída foi de $10 \mathrm{~cm}$.

Após a compactação do solo brita utilizado na base, procedeu-se à imprimação da camada superficial com uma emulsão do tipo EAI. Posteriormente à cura da imprimação, o tratamento superficial simples (TSS) foi executado como camada de rolamento sem função estrutural. Sua execução consiste na aplicação do ligante asfáltico sobre a base, seguida da distribuição do agregado. A dosagem do TSS foi executada conforme a especificação técnica do DER-SP ET-DE-P00/021 (2006), em que se adotou 1,3 1/m2 de emulsão asfáltica RR-2C e o material granular situado na Faixa Granulométrica A. 


\subsection{Avaliação da qualidade das camadas pelo ensaio de placa}

Para avaliação da qualidade de compactação das camadas foi realizado o ensaio de placa após o término da construção das camadas de subleito e de base. Este ensaio é normatizado pela DIN 18134/2012, a qual prevê três configurações distintas de placas, com diâmetros de $300 \mathrm{~mm}, 600 \mathrm{~mm}$ e $762 \mathrm{~mm}$. Entretanto, levando em consideração o efeito escala do experimento e visando simular um ensaio em pavimento, a dimensão da placa foi adaptada para ser compatível com o diâmetro e a área de contato do pneu utilizado no experimento, portanto, adotou-se uma placa de $70 \mathrm{~mm}$. Com a redução da dimensão da placa, os carregamentos foram ajustados para que se obtivesse o mesmo nível de tensões normais definidas para a placa de $300 \mathrm{~mm}$. O ensaio é realizado sobre uma placa circular submetida a um processo de carregamento em duas fases separadas em 16 estágios. O aumento ou redução das cargas foi realizado em até $60 \mathrm{~s}$ e a carga de cada estágio foi mantida constante por $60 \mathrm{~s}$.

Para realizar o ensaio utiliza-se o mesmo suporte metálico do simulador de tráfego, onde retira-se o pneu e instala-se o conjunto placa metálica, LVDT e célula de carga, ilustrado na Figura 4. Conforme a carga é aplicada, o LVDT fornece os deslocamentos verticais do conjunto e a célula de carga o carregamento.

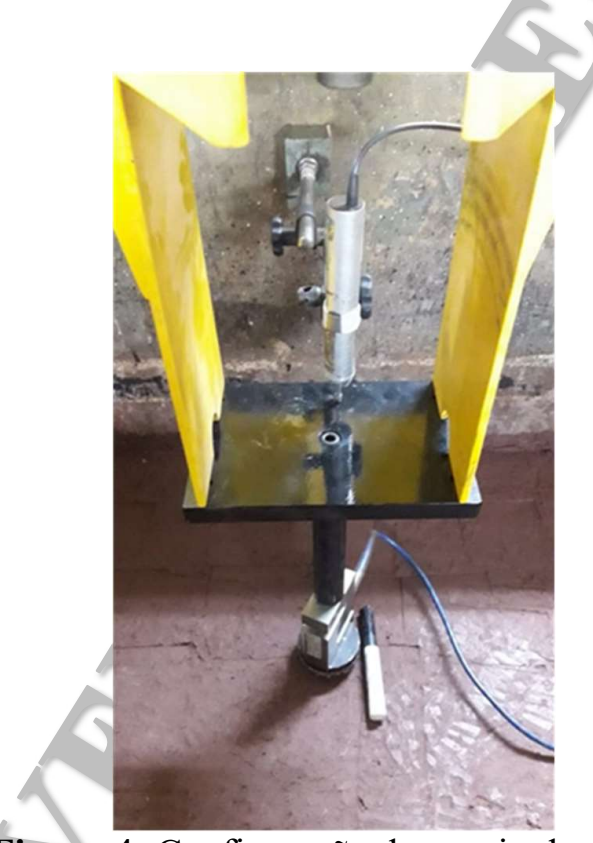

Figura 4: Configuração do ensaio de placa.

\subsection{Monitoramento do experimento}

Para monitoramento do experimento e verificação do desempenho do pavimento foram utilizados 3 tipos de instrumentos: LVDT's para leituras de deformações e deflexões, células de tensão total para leitura das tensões no subleito e uma célula de carga para controle dos carregamentos aplicados pelo simulador.

Foram utilizados 8 LVDT's ao todo, sendo 7 deles alinhados pela superfície do pavimento e um exclusivo para a leitura da bacia de recalque da trilha de roda. Os LVDT's foram separados em dois conjuntos e posicionados em faces opostas da roda. Os LVDT's foram espaçados de $15 \mathrm{~cm}$ entre si e a 10 $\mathrm{cm}$ da face do pneu. Além disso, 5 células de tensão, com uma delas posicionada na interface entre a base e o subleito e as demais ao longo da profundidade do subleito, conforme ilustrado na Figura 5. 


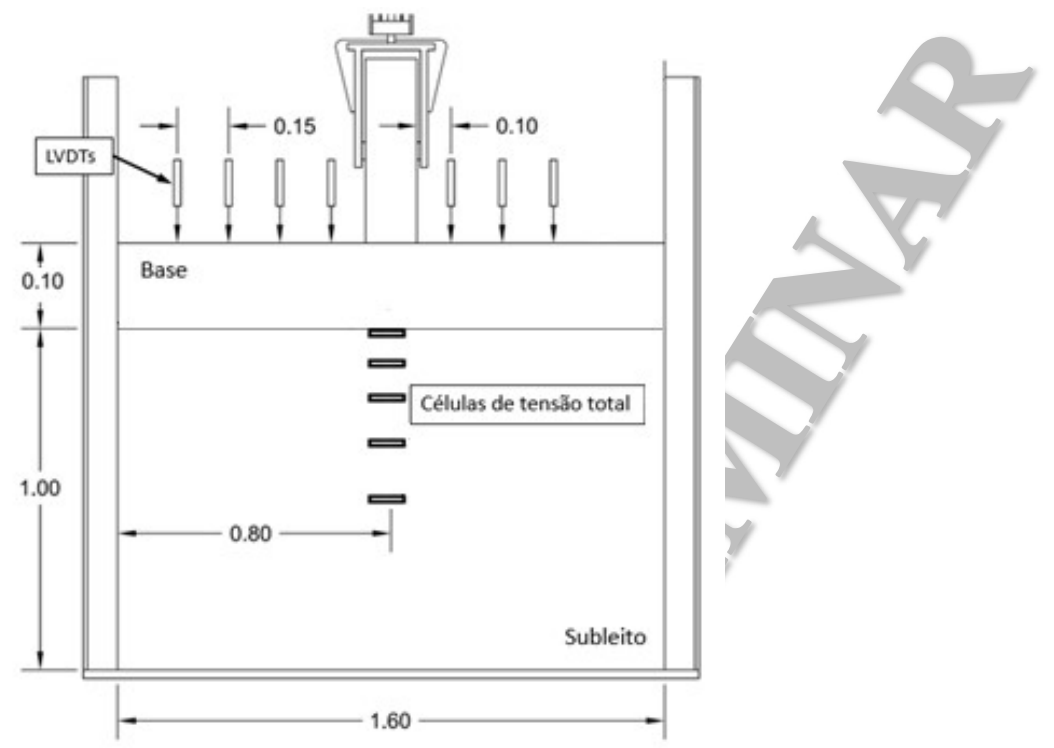

Figura 5: Seção do pavimento e instrumentação.

A medição do ATR foi realizada por meio do desenvolvimento de um suporte metálico acoplado nas bordas da caixa (Figura 6 (a)). Com o auxílio de um LVDT (Figura 6 (b)) foi executada uma varredura dos valores de deslocamento superficial transversalmente ao percurso realizado pela roda. Nos pontos próximos ao caminho da roda, as leituras foram feitas a cada $5 \mathrm{~cm}$, e os próximos das bordas a cada $8 \mathrm{~cm}$. Neste experimento, a medição do ATR de roda foi realizada após 1000, 2000, 4000, 7000, 10.000 e posteriormente a cada 10.000 até o total de 100.000 ciclos.

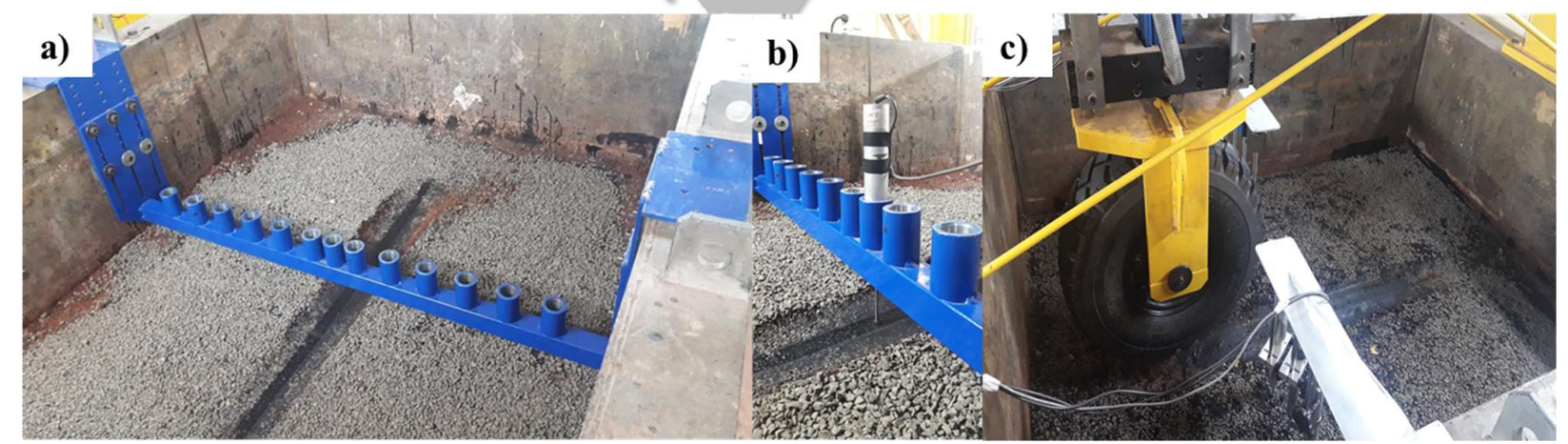

Figura 6: Instrumentação a) aparato leitura ATR; b) detalhe da leitura; c) leitura de deflexão.

\section{COLETA DE DADOS E ANÁLISE DOS RESULTADOS}

Após a montagem e a instrumentação do experimento, foi realizado o ensaio acelerado de pavimento com coletas de informações a cada $0,1 \mathrm{~s}$. Foi definido um baixo intervalo de leitura para que fosse possível obter os dados de leitura dos instrumentos durante a passagem do pneu.

Nas Figuras 7, 8 e 9, a seguir, são apresentados três resultados: o padrão de carregamentos, os deslocamentos superficiais por meio de LVDTs e as tensões no subleito a partir das células de carga e a passagem do simulador, respectivamente. 


\section{Revista PAVIMENTAÇÃO}
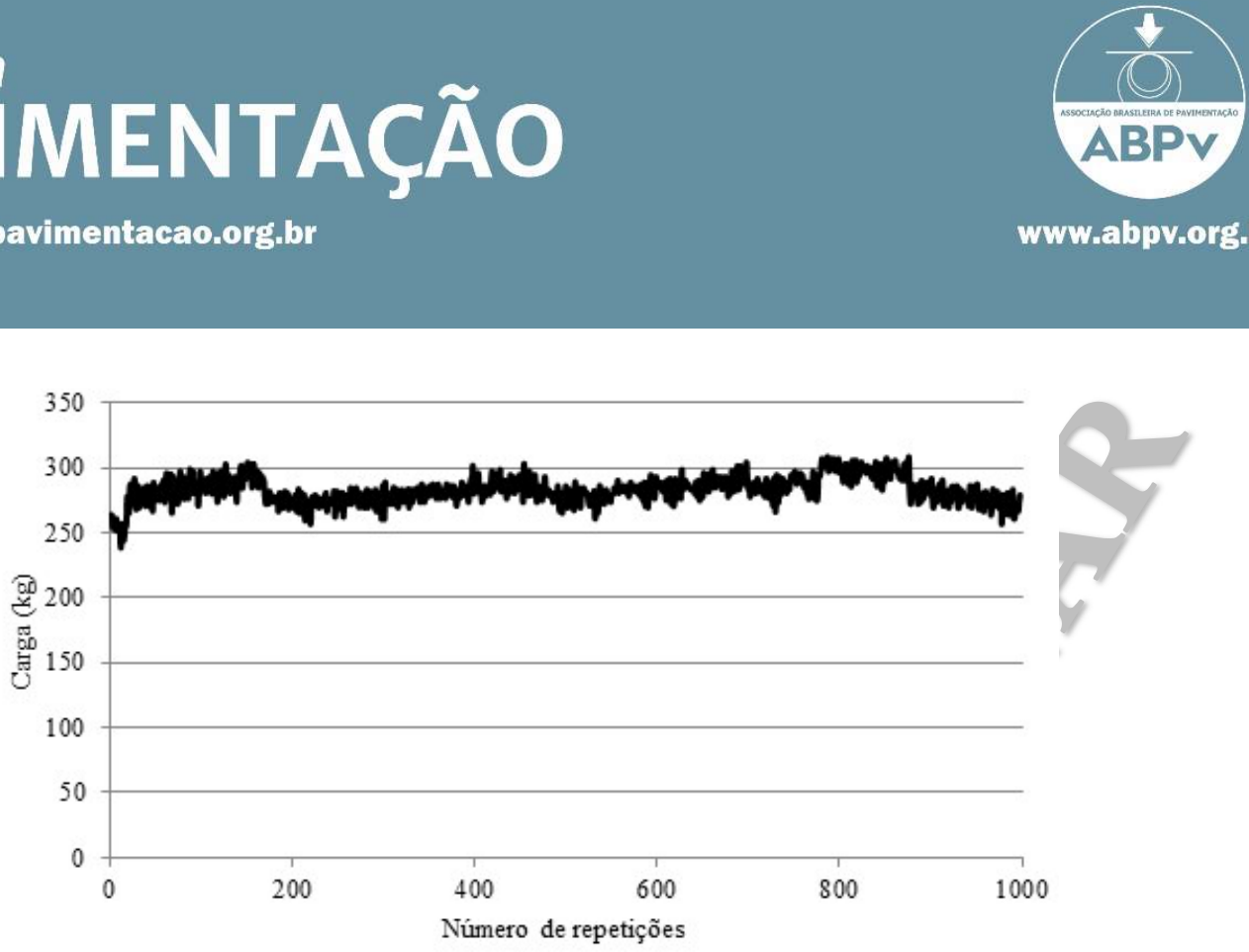

Figura 7: Monitoramento dos carregamentos.

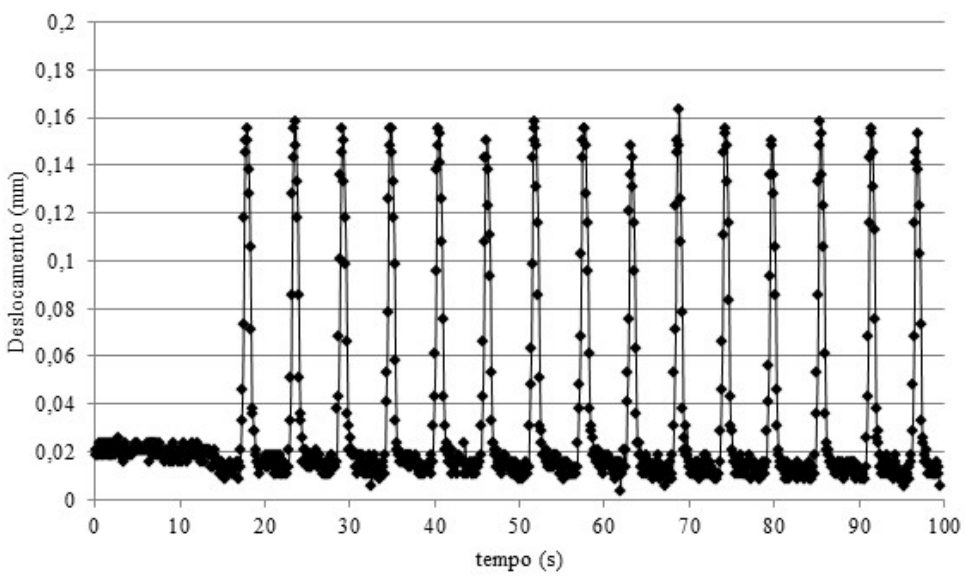

Figura 8: Deslocamentos superficiais.

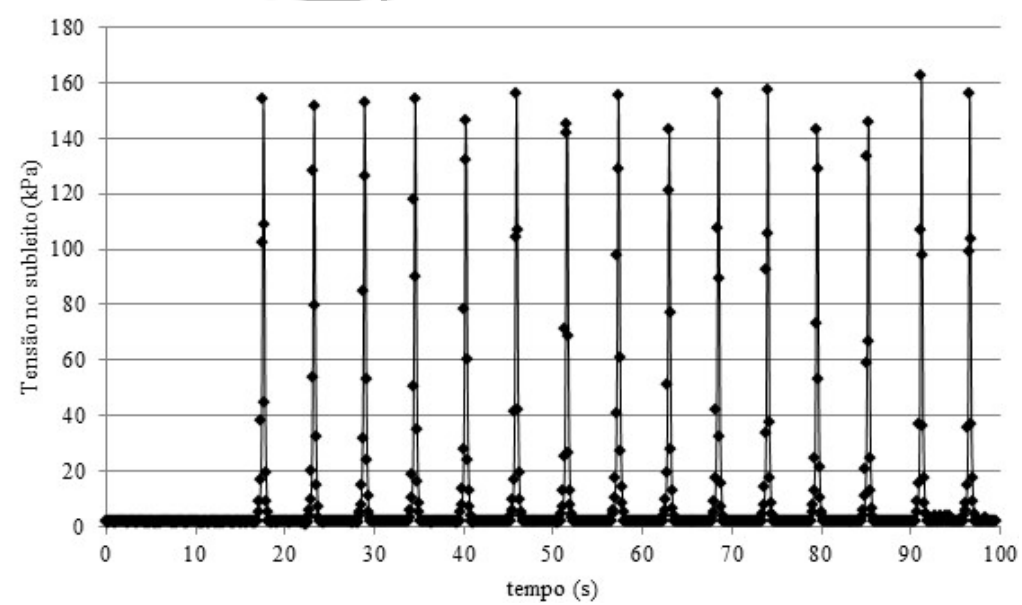

Figura 9: Tensões no subleito. 
A partir dos gráficos apresentados pode-se avaliar os resultados da instrumentação ao longo do ensaio. No gráfico de carregamentos pode-se notar que existe uma variabilidade no carregamento entre as repetições de passagens do simulador, entretanto essa variação é pequena e gera pequena influência nos resultados. Com base nos resultados provenientes dos LVDTs é possível notar o efeito da passagem da roda na deflexão superficial, uma vez que a cada passagem se obtêm um pico de leitura neste sensor. Por fim, as células de tensão total apresentam comportamento similar ao LVDT, registrando valores máximos de tensão no momento de passagem da roda.

\subsection{Módulo de deformabilidade}

Os módulos de deformabilidade das camadas de base e subleito foram mensurados através dos ensaios de placa. Os resultados dos ensaios de placa para cada camada são apresentados na Tabela 2.

Tabela 2: Resultados dos ensaios de placa.

\begin{tabular}{|c|c|c|c|c|c|c|c|c|}
\hline \multirow[b]{3}{*}{ Parâmetros } & \multicolumn{4}{|c|}{ Subleito } & \multicolumn{4}{|c|}{ Base } \\
\hline & \multicolumn{2}{|c|}{ Ensaio 1} & \multicolumn{2}{|c|}{ Ensaio 2} & \multicolumn{2}{|c|}{ Ensaio 1} & \multicolumn{2}{|c|}{ Ensaio 2} \\
\hline & $1^{\mathrm{o}}$ & $2^{\circ}$ & $1^{\mathrm{o}}$ & $2^{\circ}$ & $1^{0}$ & $2^{\circ}$ & $1^{\circ}$ & $2^{\circ}$ \\
\hline$\sigma_{0 \max }$ & 0,50 & 0,50 & 0,50 & 0,50 & 0,50 & 0,50 & 0,50 & 0,50 \\
\hline$a_{0}$ & 3,43 & 26,68 & 1,83 & 16,17 & $-0,27$ & 3,67 & $-0,06$ & 2,03 \\
\hline$a_{1}$ & 2,32 & 1,40 & $-16,75$ & 1,18 & 9,62 & 1,07 & 6,61 & 2,35 \\
\hline$a_{2}$ & 97,58 & 11,09 & 98,59 & 11,33 & $-0,07$ & 1,80 & $-1,61$ & $-1,20$ \\
\hline$E_{V}$ & 1,03 & 7,54 & 1,59 & 7,60 & 5,48 & 26,63 & 9,05 & 30,13 \\
\hline $\mathrm{E}_{\mathrm{V} 2} / \mathrm{E}_{\mathrm{V} 1}$ & \multicolumn{2}{|c|}{7,36} & \multicolumn{2}{|c|}{4,79} & \multicolumn{2}{|c|}{4,86} & \multicolumn{2}{|c|}{3,33} \\
\hline
\end{tabular}

Para os ensaios de placa foram realizadas 2 repetições para a base e o subleito, em dois locais distintos $\left(1^{\circ}\right.$ e $\left.2^{\circ}\right)$ cada um em um canto da caixa de ensaio, de forma a verificar se estas camadas apresentavam condições semelhantes ao longo de suas respectivas áreas.

Observa-se na Tabela 2, que os valores dos módulos de deformabilidade (EV) do subleito considerando os ensaios 1 e 2 apresentam valores semelhantes, indicando que esta camada está com uma condição de compactação uniforme. A camada de base por sua vez, também apresenta valores próximos, entretanto com uma variação ligeiramente maior quando comparado com o resultado do subleito. No caso dos resultados da camada de base, a variação pode ter ocorrido em função da dimensão dos agregados, que devido à dimensão reduzida da placa exercem maior influência no ensaio de placa.

\subsection{Afundamento na trilha de roda e deflexão}

O Afundamento na Trilha de Roda (ATR) é um defeito apresentado pelo pavimento, causado pelo acúmulo de deformação permanente entre as camadas devido à passagem do tráfego. A Figura 10 ilustra o ATR ocorrido no ensaio após 100.000 de passagens do simulador.

O ATR foi mensurado ao longo do experimento, sendo este realizado no perfil transversal no centro da passagem de roda, para avaliar sua evolução com o acréscimo de ciclos de simulação de cargas. A Figura 11(a) mostra os resultados de ATR do ensaio realizado. Observa-se que o ATR se desenvolve rapidamente nos ciclos iniciais do experimento, até 4000 ciclos, atingindo cerca de 16,4 $\mathrm{mm}$ de afundamento, a partir de então a tendência de acréscimo destes valores diminuem, indicando uma estabilização nos ciclos finais do experimento. Na Figura 11(b), apresenta-se a seção transversal com a evolução da bacia de recalque do 
pavimento ensaiado. São apresentados os resultados para 1000, 10.000, 50.000 e 100.000 ciclos, sendo possível avaliar a influência do carregamento ao longo do eixo transversal de passagem do simulador.

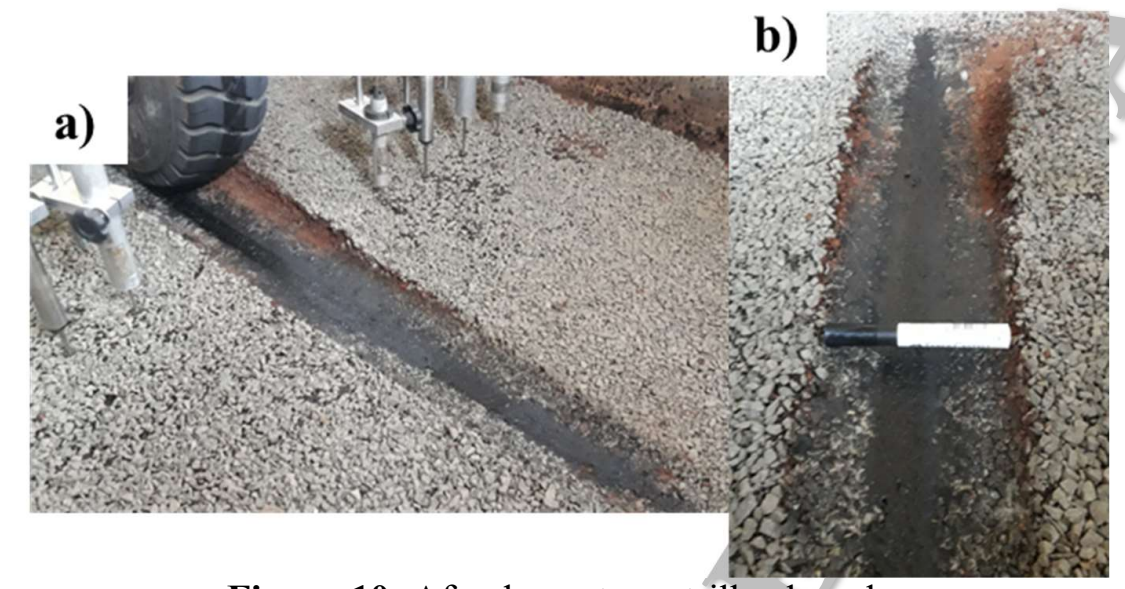

Figura 10: Afundamento na trilha de roda.
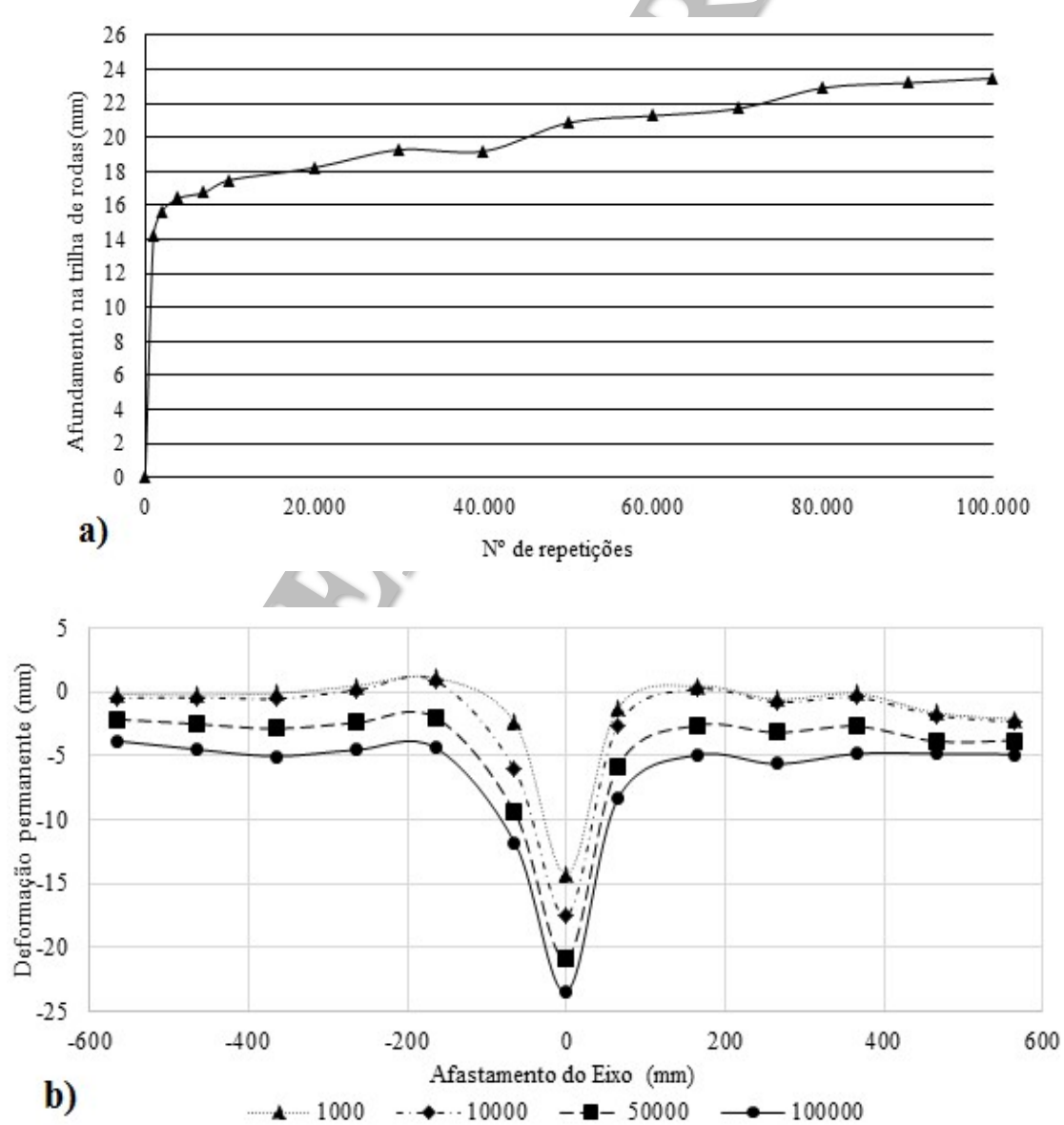

Figura 11: a) Afundamento na trilha de roda; b) Deslocamento plástico. 


\section{Revista}

A partir da Figura 11(a), observa-se que ao decorrer das 105 repetições o pavimento ainda não atingiu um patamar, mostrando que o pavimento ainda acumula alta deformação plástica das camadas. A baixa espessura da camada de base e a alta deformabilidade do subleito são os fatores principais para esse fenômeno. Verifica-se também pela Figura 11(b), que as deformações permanentes do pavimento foram concentradas na região próxima do pneu e que não há a presença de uma onda (heave) na borda externa dessa região, caracterizando que não houve espalhamento lateral da camada de rolamento.

A Figura 12 apresenta a bacia de deflexão ao final dos 1.000 ciclos para o ensaio realizado. Os resultados mostram a redução da influência da carga com o afastamento do centro de aplicação dos carregamentos (centro da trilha de roda).

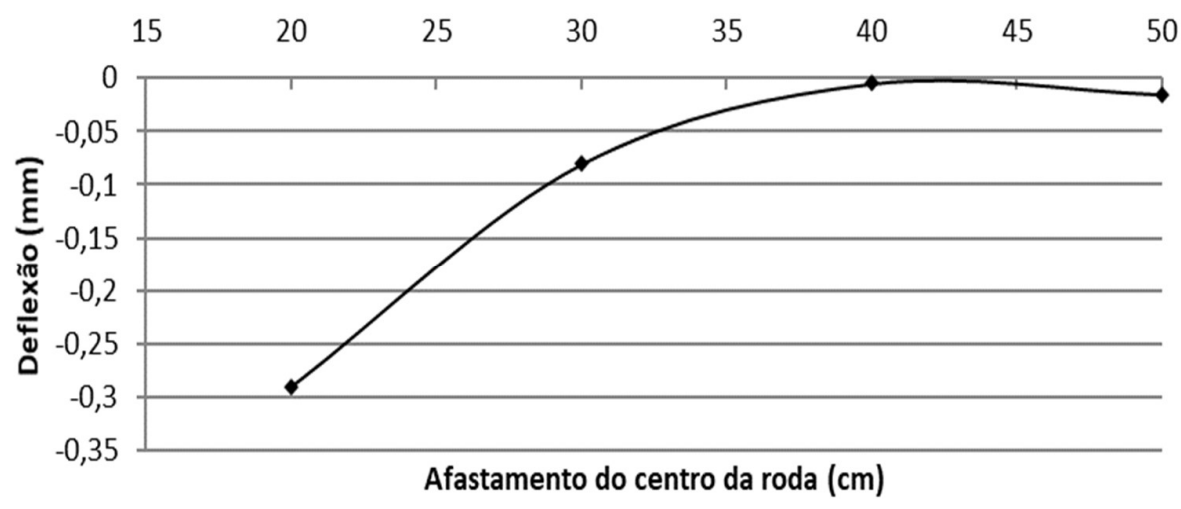

Figura 12: Bacia de deflexão após 1.000 ciclos.

Ao comparar os resultados obtidos, Figuras 11 e 12, com os apresentados em Kakuda (2010), Tang e Palomino. (2013) e Saevarsdotti e Erlingsson (2014), observa-se que apesar das estruturas serem diferentes as medidas obtidas são condizentes em magnitude, mostrando que os resultados estão de acordo com o esperado para a estrutura.

\section{CONCLUSÃO}

Um experimento para calibrar o equipamento e avaliar o desempenho de um pavimento quanto ao ATR, módulo de deformabilidade e deflexão foi apresentado neste artigo. Para as condições examinadas no ensaio realizado, as principais conclusões são:

- Os resultados dos ensaios de placa são condizentes com o esperado para as camadas de base e subleito, uma vez que os valores do módulo de deformabilidade (Ev) para a camada de menor capacidade de suporte foi muito inferior ao módulo da camada de base, de maior capacidade de suporte;

- As leituras de ATR realizadas no ensaio de APT permitiram verificar o desenvolvimento das deformações permanentes ao longo do ensaio, sendo possível identificar, a partir da inclinação da curva, os intervalos mais críticos para o acúmulo de deformações permanentes e o intervalo de estabilização das deformações;

- Os LVDTs se mostraram eficazes para leitura de deformações elásticas ao longo do eixo transversal da trilha de roda, pois foram capazes de registrar pequenas deformações. Entretanto, para obtenção de leituras mais precisas ou de magnitudes mais baixas é recomendável que se utilize LVDTs de 
cursos mais reduzidos. No caso do experimento executado o adequado seria a utilização de equipamentos de maior precisão ao se afastar do ponto de aplicação da carga;

- O simulador de tráfego se mostrou um equipamento ágil e confiável para o monitoramento e aquisição de dados, além de não apresentar falhas mecânicas ou estruturais de grande impacto no decorrer do ensaio. Essas características fazem do simulador uma ferramenta importante para pesquisas em andamento e futuras, possibilitando inúmeras configurações geométricas para as camadas de pavimentos e também a inclusão de geossintéticos e de materiais não convencionais e sustentáveis, etc.

\section{Agradecimentos}

Os autores agradecem ao CNPq, a CAPES e a FAPESP pelas bolsas de estudos e apoio financeiro, assim como as empresas fabricantes de geossintéticos pelo fornecimento de recursos e materiais.

\section{REFERENCIAS BIBLIOGRÁFICAS}

ANTUNES, L. G. S., Reforço de pavimentos rodoviários com geossintéticos. Dissertação de Mestrado, Departamento de Engenharia Civil, Universidade de Brasília, Brasília, DF. 2008.

ASSOCIAÇÃO BRASILEIRA DE NORMAS TÉCNICAS - ABNT, 1988. NBR6459: Solo: Determinação do limite de liquidez. Rio de Janeiro, 1984. 6p. NBR 7180: Solo: Determinação do limite de plasticidade. Rio de Janeiro, 1984. 3p. NBR 7181: Solo: Análise Granulométrica. Rio de Janeiro, 1984. 13p. NBR 7182: Solo: Ensaio de Compactação. Rio de Janeiro, 1988. 10p.

CORREIA, N. S., Performance of flexible pavements enchanced using geogrid-reinforced asphalt overlays. Tese de Doutoramento. EESC/USP. São Carlos, São Paulo, Brasil. 2014.

DEPARTAMENTO DE ESTRADAS DE RODAGEM DO ESTADO DE SÃO PAULO - DER-SP, 2006. Especificação técnica. ET-DE-P00/021. São Paulo, 2006.

DEPARTAMENTO DE ESTRADAS DE RODAGEM DO ESTADO DE SÃO PAULO - DER-SP, 2006. Especificação técnica. ET-DE-P00/006. São Paulo, 2006.

DEPARTAMENTO NACIONAL DE ESTRADA DE RODAGEM - DNER, 1997. ME -254/97 Solos compactados em equipamento miniatura -Mini-CBR e expansão. Método de ensaio. Departamento Nacional de Infraestrutura de Transportes (DNIT). Rio de Janeiro. 1997. 14 p

DIN 18134:2012-04. Soil - testing procedures and testing equipment - Plate load test. Berlin, Germany, 2012.

GONÇALVES, F.J.P., Estudo do desempenho de pavimentos flexíveis a partir de instrumentação e ensaios acelerados. Tese de Doutorado, UFRGS, Rio Grande do Sul. 2002.

HOLTZ, R.D., CHRISTOPHER, B.R.; BERG, R.R., Geosynthetic design and construction guidelines. Federal Highway Administration, Washington, DC, FHWA-HI-98- 038, 460 p. 1998.

KAKUDA, F. M., Desenvolvimento e a utilização de um equipamento de grandes dimensões na análise do comportamento mecânico de uma seção de pavimento sob carregamento cíclico. Tese de Doutorado. USP/EESC, São Carlos, Brasil. 2010.

METCALF, J. B., Application of Full-Scale Accelerated Pavement Testing. NCHRP Synthesis of Highway Practice 235: Transportation Research Board, National Research Council, Washington, D.C., 110 pp. 1996.

RECK, N.C., Mechanistic empirical design of geogrid reinforced paved flexible pavements. Jubilee symposium on Polymer Grid Reinforcement, Institute of Civil Engineers, London, England. 2009.

SAEVARSDOTTIR, T E ERLINGSSON, S., Modelling of responses and rutting profile of a flexible pavement structure in a heavy vehicle simulator test, Road Materials and Pavement Design, DOI: 10.1080/14680629.2014.939698. 2014

SILVA, B. A., Análise mecânica de um pavimento rodoviário submetido à oscilação do lençol freático simulada em modelo físico de verdadeira grandeza. Tese de Doutorado. Rio de Janeiro: UFRJ/COPPE. 2009.

TANG, X., STOFFELS, S. M., E PALOMINO, A. M., Resilient and permanent deformation characteristics of unbound pavement layers modified by geogrids. Transportation Research Record, 2369, 3-10. doi:10.3141/2369-01. 2013

TIELKING, JOHN \& ROBERTS, FREDDY., Tire Contact Pressure and Its Effect on Pavement Strain. Journal of Transportation Engineering-asce, v.113. doi: 10.1061/(ASCE)0733-947X(1987)113:1(56). 1987. 